DOI: 10.17516/1997-1397-2021-14-6-735-745

УДК 517.9, 621.9

\title{
On the Parallel Kinematics of the FET Stretching Press in the Stretch Forming Operations in the Manufacture of Parts with Complex Spatial Geometry
}

\author{
Anton A. Krivenok* \\ Branch of PJSC Company "Sukhoi" \\ "Komsomolsk-on-Amur Aviation Plan named after Yu.A. Gagarin" \\ Komsomolsk-on-Amur, Russian Federation \\ Anatoly A. Burenin ${ }^{\dagger}$ \\ Institute of Mechanical Engineering and Metallurgy FEB RAS, \\ Khabarovsk Federal Research Center FEB RAS \\ Khabarovsk, Russian Federation
}

Received 28.07.2021, received in revised form 03.08.2021, accepted 20.09.2021

\begin{abstract}
The kinematics of a stretching press mechanism of a parallel structure are investigated. The kinematic dependences aimed at setting the spatial position of the working elements of a cross-stretching press of FET type, which allow positioning its jaws at any time during the technological operations, are obtained. The forward and inverse control kinematics problems of the jaw mechanism stretching press are solved.
\end{abstract}

Keywords: stretch forming, stretching press, FET, parallel structure kinematics, forward and inverse kinematics problems.

Citation: A.A. Krivenok, A.A. Burenin On the Parallel Kinematics of the FET Stretching Press in the Stretch Forming Operations in the Manufacture of Parts with Complex Spatial Geometry, J. Sib. Fed. Univ. Math. Phys., 2021, 14(6), 735-745. DOI: 10.17516/1997-1397-2021-14-6-735-745.

\section{Introduction}

Improving the functional qualities of modern airplane airframes is inextricably linked with the tightening of requirements for their aerodynamic shapes while increasing the strength properties of their structural elements. Compliance with the requirements in the production process is achieved mainly [1], through irreversible deformation of the workpiece during forming and stretching. In spite of large displacements and rotations in the workpiece, small deformation theory methods remain acceptable in calculations of irreversible deformation during the forming of thin-walled structural elements [2]. These methods are not applicable in the technological operation of the stretching process. The workpiece is not thin-walled, its middle surface cannot be considered non-stretchable. Hence, all calculations must be carried out using large deformation theory $[3,4]$, which complicates them considerably. Until now, we have only fundamental prerequisites for this $[4,5]$. The process of producing large deformations during stretch forming of a workpiece, simultaneously due to the viscous properties of the material (creep) and its plastic

\footnotetext{
*baikal-190@yandex.ru https://orcid.org/0000-0001-5683-4416

†burenin@iacp.dvo.ruｈttps://orcid.org/0000-0003-4502-9547

(C) Siberian Federal University. All rights reserved
} 
properties (flow), is not studied in depth. The results of mathematical modeling of this process would be of great help in creating control programs ( $\mathrm{NC}$ ) and choice the operating modes of stretching presses.

The creation of a NC meets a different problem, which is the need for accurate positioning of the jaws under heavy loads. When it is necessary to ensure accurate spatial geometry of the product, this is not an easy task. In this article we will focus on such a problem as it relates to the aircraft industry.

In the aviation industry, specialized stretching presses from the French company ACB, such as FEKD, FEL, FET etc., are widely used to carry out the stretch forming process of workpieces [6]. Of great interest is the range of hydraulic cross-stretching presses of the FET type with their parallel kinematics, which ensures high mobility of the jaws at high loads (Fig. 1). The press has two rectilinear jaws, the movement of which ensures the shaping of the workpiece along the stretching punch. Each jaw is positioned by changing the length of four hydraulic cylinders: two horizontal and two vertical. Such a design of stretching presses and the control system used on them provides for the production of shell parts of a complex spatial shape.

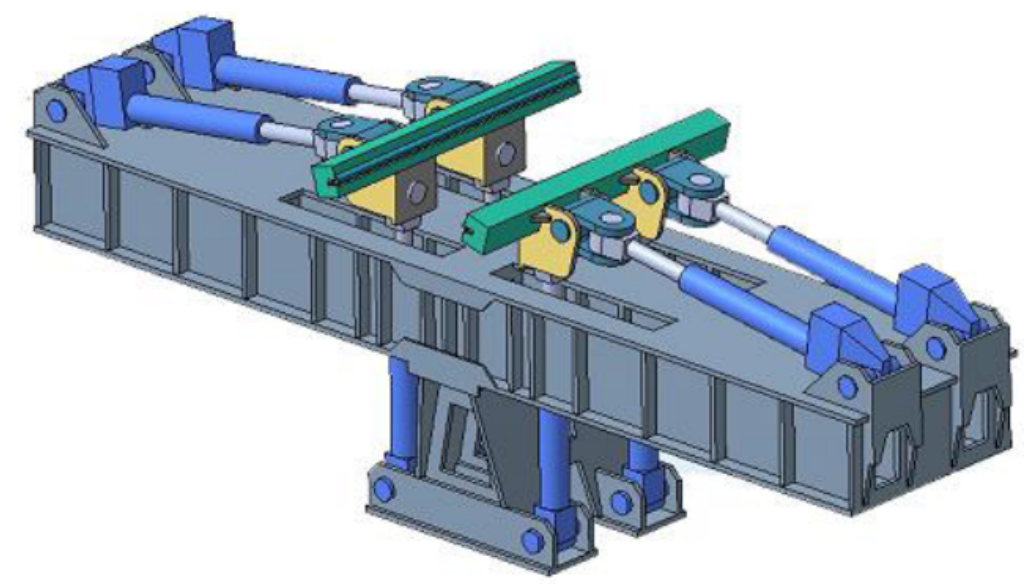

Fig. 1. Cross-stretching press FET type

When calculating $\mathrm{NC}$ for the numerical control system $(\mathrm{CNC})$ of the press it is necessary to take into account such factors as press kinematics, punch geometry and its location relative to the press table, geometrical and mechanical characteristics of the workpiece, as well as friction conditions. For stretch presses of ACB there are two specialized CAM / CAE - systems that simulate the process of stretching the workpiece and calculate the $\mathrm{NC}$ for the control system of the relevant press: S3F and FormCAM. These systems have limitations on the accuracy of modeling, the flexibility of setting the deformation scheme and editing the NC $[7,8]$. Therefore, to search for the optimal mode of forming, a set of various software tools is used, which are aimed at solving the following problems [9-12]:

- the NC calculation is performed using a mathematical model that describes the press kinematics according to a given workpiece deformation strategy;

- the calculated trajectory of press working elements is checked using the kinematic model in the CAD system, where the possibility of collisions between press elements and technological tooling is checked;

- the workpiece deformation process is analyzed in the CAE system, where the behavior of the 
workpiece during its contact with the punch and jaws of the press is checked.

There are works describing the kinematics of the FET press as a planar mechanism $[7,8]$. This solution allows the coordinates of the jaw elements to be calculated with analytical precision from the control parameters and, inversely, the control parameters from the jaw coordinates. The solutions presented show good results if they are used in the forming of parts with single curvature and symmetry in the direction of stretching [13-15]. Fig. 2 shows a diagram of the jaw nodes displacement along the $\mathrm{Y}$ axis when it is rotation around the $\mathrm{Z}$ and $\mathrm{X}$ axes. Displacement of the clamped workpiece along the $\mathrm{Y}$ axis relative to the initial position can cause the load reduction on one side of the workpiece and the load increase on the other side. This can cause the workpiece to slide off the punch, creasing of corrugations on the workpiece or its damage $[16,17]$.

In order to be ensuring to calculate the NC for asymmetrical parts of complex spatial geometry with a double curvature, a kinematic analysis of the parallel structure mechanisms of an FET stretching press was carried out.

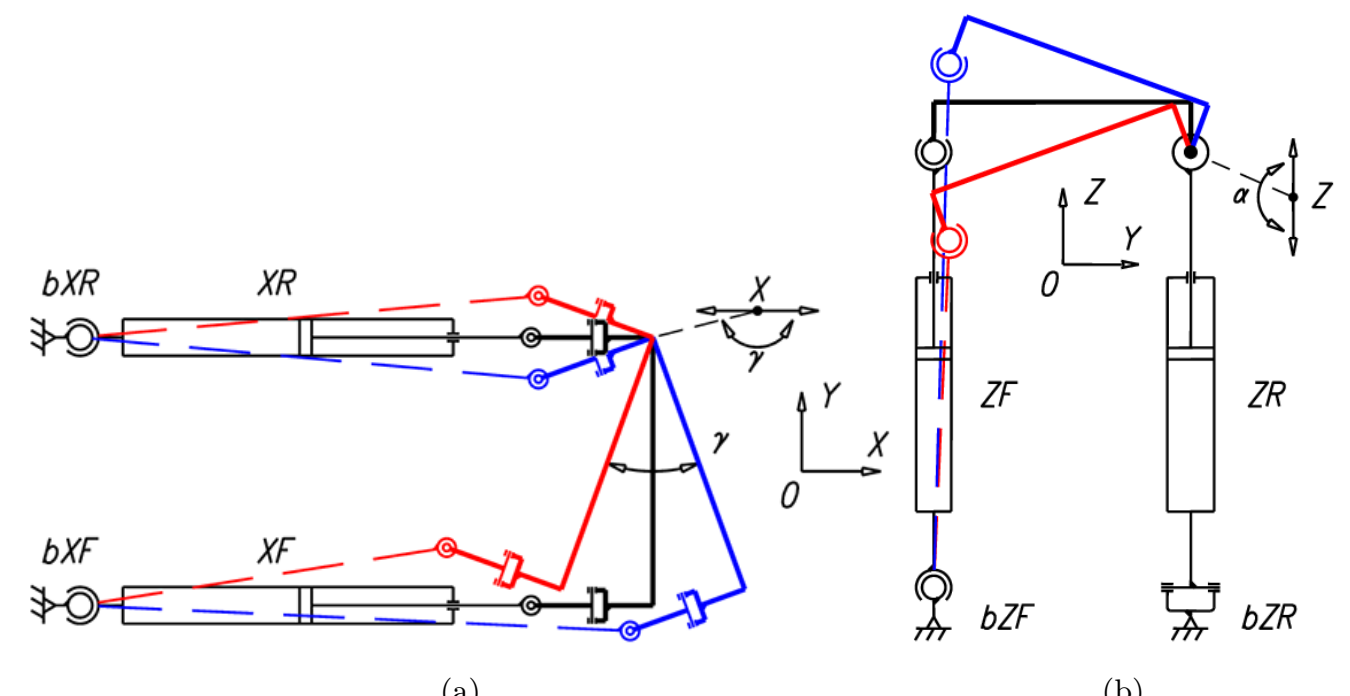

(a)

(b)

Fig. 2. Displacement of the jaw nodes along the $\mathrm{Y}$ axis when it is rotation around the $\mathrm{Z}$ and $\mathrm{X}$ axes: $\mathrm{a}-$ top view (rotation around the $\mathrm{Z}$ axis), $\mathrm{b}$ - right view (rotation around the $\mathrm{X}$ axis)

\section{Construction of FET stretching press}

The FET stretch press is symmetrical from right to left, so let's analyze the kinematics of one jaw mechanism (Fig. 3). The structure of the jaw mechanism of the FET is designed as a spatial mechanism with a closed kinematic chain $[18,19]$. The kinematic links topology of a FET press with parallel structure can be written as follows:

$$
2-(S \underline{P} R R)-(S \underline{P} S)-(R \underline{P} R R),
$$

where $S$ is spherical kinematic pair, $P$ is progressive kinematic pair, $R$ is rotary kinematic pair. Active kinematic pairs are underlined.

The horizontal cylinders $X F$ and $X R$ are attached to the press table frame by spherical joints 
this ensures that they rotate when the jaw moves. The horizontal cylinders are equipped with intermediate links for connection to the jaws. The $Z F$ vertical cylinder is attached to the press table frame and to the jaw by spherical joints. The vertical cylinder $Z R$ has a larger diameter and has a supporting function. The $Z R$ cylinder is connected to the press table by a sleeve which limits its movement in the vertical plane. Rotation along the vertical axis is possible due to the rotation of the vertical cylinder rod inside the $Z R$ cylinder. Hydraulic actuators with precision hydraulics are used to change cylinder lengths.

The jaw node is moved in coordinates $(x, z)$ along the two linear axes and coordinates $(\alpha, \gamma)$ around the two rotary axes by coordinated changes in the lengths of the four hydraulic cylinders (Fig. 4). The inclination angle $\beta$ of the jaw depends on its coordinates $(x, z)$.

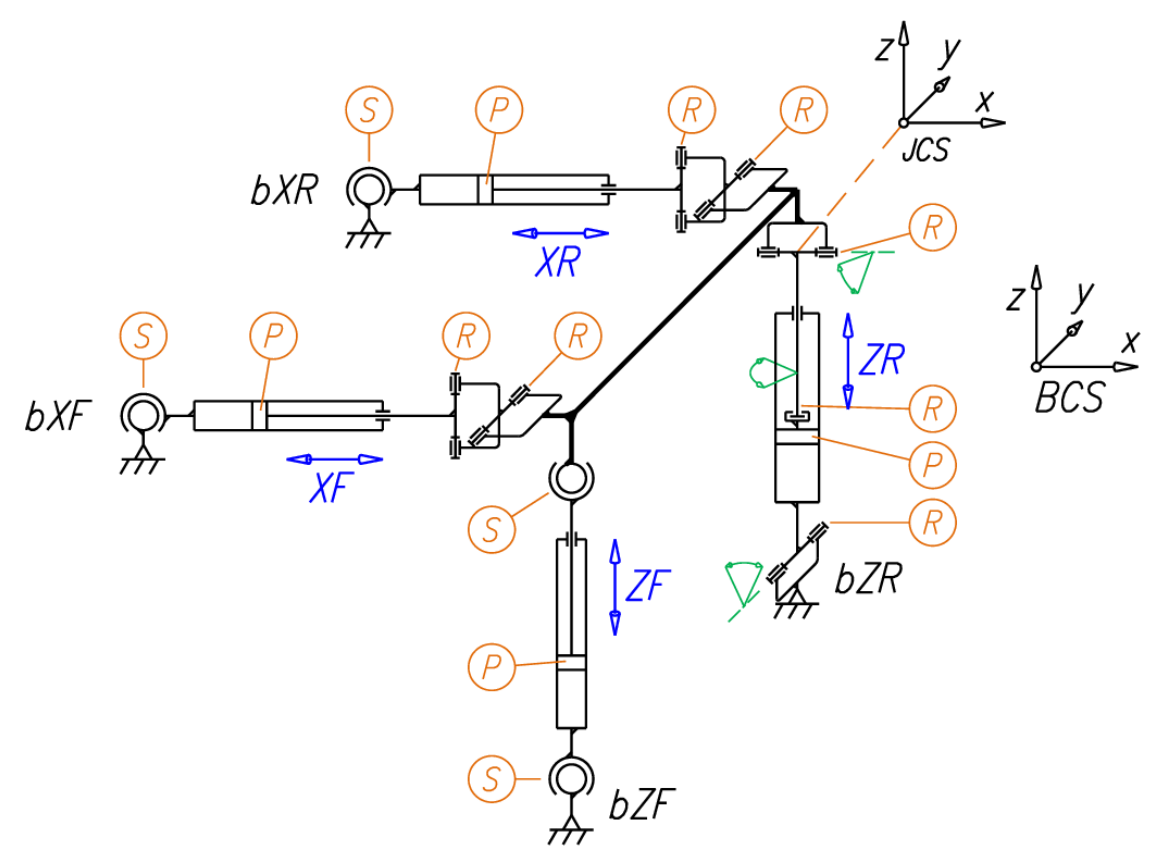

Fig. 3. Kinematic scheme of the FET press jaw

\section{Forward and inverse kinematics problem of the FET press jaw}

Parallel structure mechanisms cannot be used without solving forward and inverse kinematics problems, which are more difficult to solve than for traditional manipulators [20,21]. The forward kinematics problem determines the position of the executive element (press jaw) in space for a given value of generalized coordinates (length of hydraulic cylinder). The inverse kinematics problem determines the value of the generalized coordinates for a given position in space of the press jaw.

\section{Solving the inverse kinematics problem of the FET press jaw}

The origin of the jaw coordinate system (JCS) is the $\mathbf{M}$ joint (Fig. 4), which moves in the plane of rotation of the $Z R$ cylinder and depends on the following parameters $[x, z, \alpha, \gamma]$, where: $x$ and 
$z$ are the coordinates of the $\mathbf{M}$ joint in the base coordinate system of the press table (BCS); $\alpha$ and $\gamma$ are the angles of rotation of the jaw around the origin of the JCS. The generalized coordinates are the lengths of the progressive pairs - hydraulic cylinders $\mathbf{Q}=[X R, X F, Z R, Z F]^{T}$.

To determine the $\mathbf{Q}$ vector of the hydraulic cylinder lengths at a given jaw position $\mathbf{M}$ joint and its angle of rotation, the position of all the jaw joints in the BCS must be determined. To do this, transfer the coordinates of the $P$ joints of the jaw from JCS to BCS and rotate by angles $[\alpha, \beta, \gamma]$ around the $\mathbf{M}$ joint.

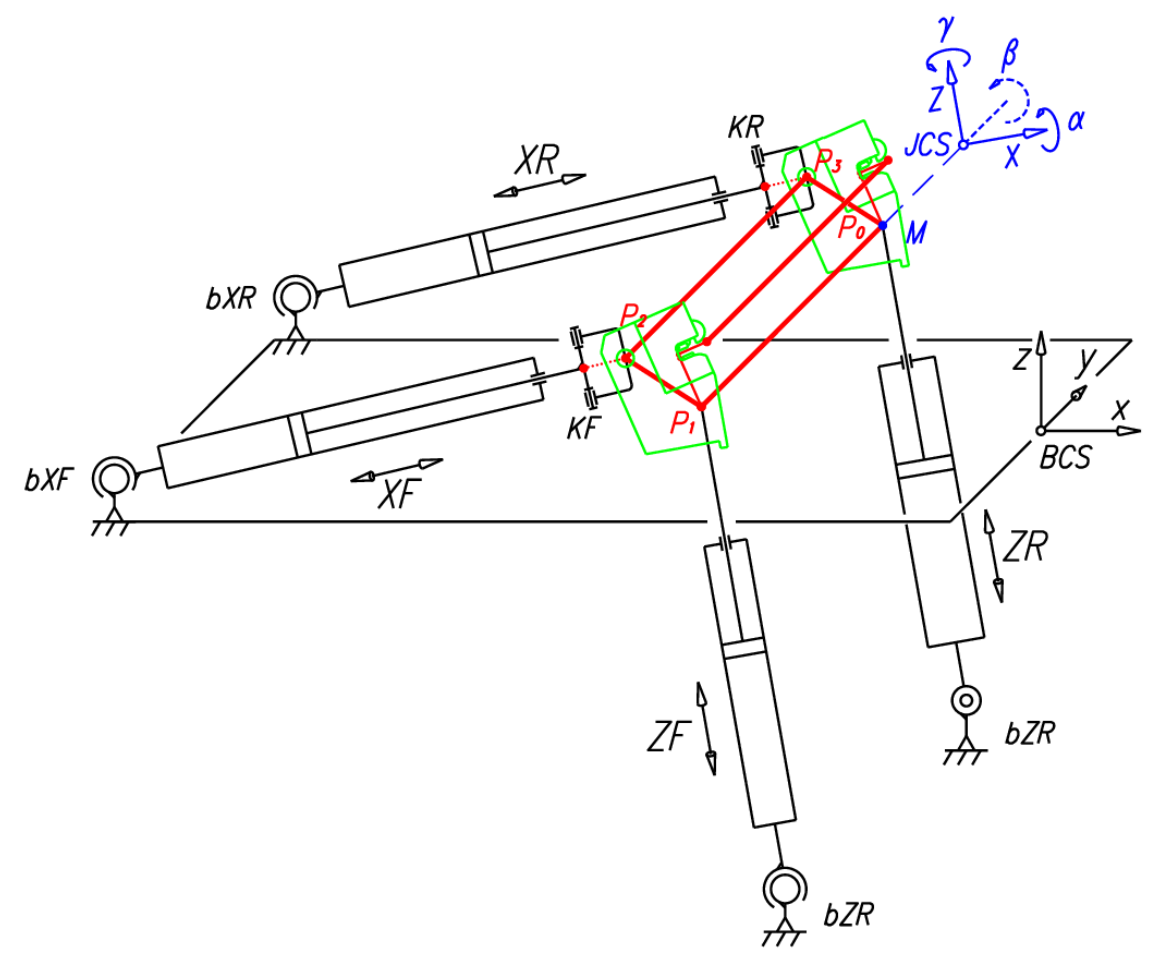

Fig. 4. Scheme for defining the press jaw nodes

In developing the mathematical model of the FET press, it is proposed to use the matrix apparatus of homogeneous transformations proposed by J. Denavit and R. Hartenberg [22-24].

The coordinates of the jaw joints in the press table coordinate system BCS can be determined by the following formula:

$$
P^{\prime}=P \cdot R_{x}(\alpha) \cdot R_{y}(\beta) \cdot R_{z}(\gamma) \cdot T,
$$

where $P$ is the matrix of the jaw joints coordinates in the jaw coordinate system (JCS)

$$
P=\left(\begin{array}{llll}
P 0_{x} & P 0_{y} & P 0_{z} & 1 \\
P 1_{x} & P 1_{y} & P 1_{z} & 1 \\
P 2_{x} & P 2_{y} & P 2_{z} & 1 \\
P 3_{x} & P 3_{y} & P 3_{z} & 1
\end{array}\right)
$$

$R_{x}(\alpha)$ is the rotation matrix by angle $\alpha$ around the $\mathrm{Ox}$ axis

$$
R_{x}(\alpha)=\left(\begin{array}{cccc}
1 & 0 & 0 & 0 \\
0 & \cos (\alpha) & \sin (\alpha) & 0 \\
0 & -\sin (\alpha) & \cos (\alpha) & 0 \\
0 & 0 & 0 & 1
\end{array}\right),
$$


$R_{y}(\beta)$ is the rotation matrix by angle $\beta$ around the Oy axis

$$
R_{y}(\beta)=\left(\begin{array}{cccc}
\cos (\beta) & 0 & -\sin (\beta) & 0 \\
0 & 1 & 0 & 0 \\
\sin (\beta) & 0 & \cos (\beta) & 0 \\
0 & 0 & 0 & 1
\end{array}\right)
$$

$R_{z}(\gamma)$ is the rotation matrix by angle $\gamma$ around the $\mathrm{Oz}$ axis

$$
R_{z}(\gamma)=\left(\begin{array}{cccc}
\cos (\gamma) & \sin (\gamma) & 0 & 0 \\
-\sin (\gamma) & \cos (\gamma) & 0 & 0 \\
0 & 0 & 1 & 0 \\
0 & 0 & 0 & 1
\end{array}\right)
$$

$T$ is the transfer matrix of the JCS origin to BCS

$$
T=\left(\begin{array}{cccc}
1 & 0 & 0 & 0 \\
0 & 1 & 0 & 0 \\
0 & 0 & 1 & 0 \\
M_{x} & M_{y} & M_{z} & 1
\end{array}\right)
$$

where $\mathbf{M}$ is the joint coordinates in BCS, which correspond to the position of the jaw in the plane of the ZR hydraulic cylinder rotation around the bZR joint

$$
M=\left(\begin{array}{c}
x \\
b Z R_{y} \\
z
\end{array}\right) .
$$

The angles $\alpha$ and $\gamma$ are set depending on the required position of the jaw, angle $\beta$ depends on the joint position $\mathbf{M}$ and is defined by the following formula:

$$
\beta=\frac{\pi}{2}-\arccos \left(\frac{M_{x}-b Z R_{x}}{Z R}\right),
$$

where $Z R$ is the length of the hydraulic cylinder, which is determined by the distance between the joints coordinates of the press table bZR and the jaw $\mathbf{M}$ in BCS. Similarly, the hydraulic cylinder length $Z F$ is the distance between the joints $\mathbf{b Z F}$ and $\mathbf{P} \mathbf{1}^{\prime}$ in BCS:

$$
\begin{aligned}
& Z R=\sqrt{\sum_{i}\left(\mathbf{b Z R}_{i}-\mathbf{M}_{i}\right)^{2}}, \\
& Z F=\sqrt{\sum_{i}\left(\mathbf{b Z F}_{i}-\mathbf{P} \mathbf{1}^{\prime}{ }_{i}\right)^{2}},
\end{aligned}
$$

where $i=0, \cdots, 2$.

To determine the hydraulic cylinder lengths $X R$ and $X F$, determine the coordinates of the intermediate link joints $\mathbf{K R}$ and $\mathbf{K F}$ (Fig. 5)

$$
\begin{aligned}
& \mathbf{K R}=\mathbf{P} 3^{\prime}+\frac{\mathbf{L R}}{|\mathbf{L R}|} \cdot L v, \\
& \mathbf{K F}=\mathbf{P 2}^{\prime}+\frac{\mathbf{L F}}{|\mathbf{L F}|} \cdot L v,
\end{aligned}
$$


where $\mathbf{P 2} \mathbf{2}^{\prime}$ and $\mathbf{P 3}^{\prime}$ are the joint coordinates of the connecting intermediate links to the jaw in the BCS; $L v$ is the link length is defined as the distance between the hinges of the intermediate link.

Vectors $\mathbf{L R}$ and $\mathbf{L F}$ are the projections of vectors $\mathbf{B R}$ and $\mathbf{B F}$ on the plane with normal $\mathbf{C S}$, which corresponds to the rotation axis of the intermediate links in joints $\mathbf{P} 3^{\prime}$ and $\mathbf{P 2}{ }^{\prime}$. One of the ways to define vectors $\mathbf{L R}$ and $\mathbf{L F}$ is as follows:

$$
\begin{aligned}
& \mathbf{L R}=\frac{\mathrm{CS} \times \frac{\mathrm{BR} \times \mathrm{CS}}{|\mathbf{C S}|}}{|\mathbf{C S}|}, \\
& \mathbf{L F}=\frac{\mathrm{CS} \times \frac{\mathrm{BF} \times \mathbf{C S}}{|\mathbf{C S}|}}{|\mathbf{C S}|},
\end{aligned}
$$

where $\mathbf{B R}$ and $\mathbf{B F}$ are vectors from jaw joints $\mathbf{P} 3^{\prime}$ and $\mathbf{P} \mathbf{2}^{\prime}$ to horizontal hydraulic cylinder joints $\mathbf{b X R}$ and $\mathbf{b X F}$, respectively

$$
\begin{gathered}
\mathbf{B R}=\mathbf{b X R}-\mathbf{P 3}^{\prime}, \\
\mathbf{B F}=\mathbf{b X F}-\mathbf{P} 2^{\prime}, \\
\mathbf{C S}=\mathbf{P} 3^{\prime}-\mathbf{P 2}^{\prime} .
\end{gathered}
$$

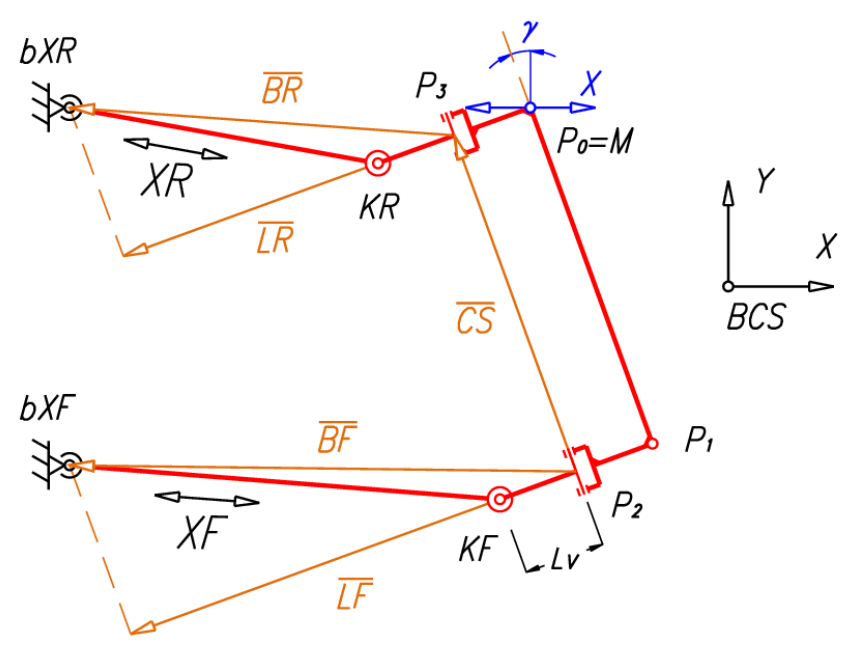

Fig. 5. Scheme for defining the press jaw nodes

The length of the hydraulic cylinders $X F$ and $X R$ is determined by the distance between the joints coordinates of the press table $\mathbf{b X F}, \mathbf{b X R}$ and the intermediate links $\mathbf{K F}, \mathbf{K R}$ in BCS

$$
\begin{aligned}
X F & =\sqrt{\sum_{i}\left(\mathbf{b} \mathbf{X} \mathbf{F}_{i}-\mathbf{K} \mathbf{F}_{i}\right)^{2}}, \\
X R & =\sqrt{\sum_{i}\left(\mathbf{b} \mathbf{X} \mathbf{R}_{i}-\mathbf{K R}_{i}\right)^{2}},
\end{aligned}
$$

where $i=0, \cdots, 2$.

The kinematic dependencies obtained in equations (1-7) determine the generalised coordinates $\mathbf{Q}$ by a given press jaw position $\mathbf{M}=[x, z, \alpha, \gamma]^{T}$. 


\section{Solving the forward kinematics problem of the FET press jaw}

Determine the jaw positions $\mathbf{M}=[x, z, \alpha, \gamma]^{T}$ by the generalized coordinates of hydraulic cylinder lengths $\mathbf{Q}=[X R, X F, Z R, Z F]^{T}$ by solving the forward kinematics problem $[23,24]$ as:

$$
\mathbf{M}=J \cdot \mathbf{Q}
$$

where $\mathrm{J}$ is a forward Jacobi matrix is as:

$$
J_{i, j}=\frac{\partial f_{i}(\mathbf{Q})}{\partial \mathbf{Q}_{j}}, i=0, \cdots, 3, j=0, \cdots, 3 .
$$

In this problem formulation it is difficult to determine the partial derivatives of the function $f(\mathbf{Q})$. Therefore the solution of the forward problem can be implemented by Newton's iteration method, which consists of the following steps:

1) the initial position $\mathbf{M}^{[k]}$ is set, where $k=0$ is the iteration number;

2) the vector of generalized coordinates $\mathbf{q}^{[k]}=F\left(\mathbf{M}^{[k]}\right)$ is determined. The function $F(\mathbf{M})$ is the solution to the inverse kinematic problem of the JCS to BCS transformation presented in equations (1-7);

3) the deviations $\Delta \mathbf{q}^{[k]}=\mathbf{Q}-\mathbf{q}^{[k]}$ of the current generalized coordinates $\mathbf{q}^{[k]}$ from the given $\mathbf{Q}$ are determined;

4) the deviations $\Delta \mathbf{M}^{[k]}$ of the press jaw position are determined. To do this it is necessary to determine the Jacobi matrix for solving the inverse kinematics problem based on equation (8)

$$
\mathbf{q}=J^{-1} \cdot \mathbf{M} \text { или } \mathbf{q}=J r \cdot \mathbf{M} .
$$

For the current position $\mathbf{M}^{[k]}$, the elements of the matrix $J r^{[k]}$ are determined by the method of numerical differentiation and are as follows:

$$
\begin{gathered}
J_{i, j}^{[k]}=\frac{\partial F_{i}\left(M^{[k]}\right)}{\partial M_{j}}=\frac{F_{i}\left(M^{[k]}+\Delta M_{j}\right)-F_{i}\left(M^{[k]}\right)}{\Delta M_{j}} \\
J r=\left(\begin{array}{llll}
\frac{\partial F_{X R}(x, z, \alpha, \gamma)}{\partial x} & \frac{\partial F_{X R}(x, z, \alpha, \gamma)}{\partial z} & \frac{\partial F_{X R}(x, z, \alpha, \gamma)}{\partial \alpha} & \frac{\partial F_{X R}(x, z, \alpha, \gamma)}{\partial \gamma} \\
\frac{\partial F_{X F}(x, z, \alpha, \gamma)}{\partial x} & \frac{\partial F_{X F}(x, z, \alpha, \gamma)}{\partial z} & \frac{\partial F_{X F}(x, z, \alpha, \gamma)}{\partial \alpha} & \frac{\partial F_{X F}(x, z, \alpha, \gamma)}{\partial \gamma} \\
\frac{\partial F_{Z R}(x, z, \alpha, \gamma)}{\partial x} & \frac{\partial F_{Z R}(x, z, \alpha, \gamma)}{\partial z} & \frac{\partial F_{Z R}(x, z, \alpha, \gamma)}{\partial \alpha} & \frac{\partial F_{Z R}(x, z, \alpha, \gamma)}{\partial \gamma} \\
\frac{\partial F_{Z F}(x, z, \alpha, \gamma)}{\partial x} & \frac{\partial F_{Z F}(x, z, \alpha, \gamma)}{\partial z} & \frac{\partial F_{Z F}(x, z, \alpha, \gamma)}{\partial \alpha} & \frac{\partial F_{Z F}(x, z, \alpha, \gamma)}{\partial \gamma}
\end{array}\right) .
\end{gathered}
$$

Then the deflection of the jaw position $\Delta \mathbf{M}^{[k]}$ is as follows:

$$
\Delta \mathbf{M}^{[k]}=\left(J r^{-1}\right)^{[k]} \cdot \Delta \mathbf{q}^{[k]}
$$

5 ) if the deviation of the current generalized coordinates is larger than the permissible error $\left|\Delta \mathbf{q}_{i}^{[k]}\right|>\varepsilon_{i}$, then the current position $\mathbf{M}^{[k+1]}=\mathbf{M}^{[k]}+\Delta \mathbf{M}^{[k]}, k=k+1$, and go to step 2 to determine the generalized coordinate vector $\mathbf{q}^{[k]}$ for the new position $\mathbf{M}^{[k]}$. This approach allows the jaw position $\mathbf{M}$ to be determined with a given accuracy $\varepsilon$ from the given hydraulic cylinder lengths $\mathbf{Q}$. 


\section{Conclusion}

On the basis of the obtained kinematic dependences for determining the working elements position of the FET stretching press and the developed solutions of forward and inverse kinematics problems, the software for PC with the implemented mathematical model of the press jaw control system was developed. The software allows visualizing the work stages of the FET stretching press according to NC, editing NC by changing the jaw position or the parameters of hydraulic cylinders (Fig. 6). The software also allows creating a NC based on a given trajectory of the press jaws movement, which can include various deformation schemes by stretch forming of the workpiece.

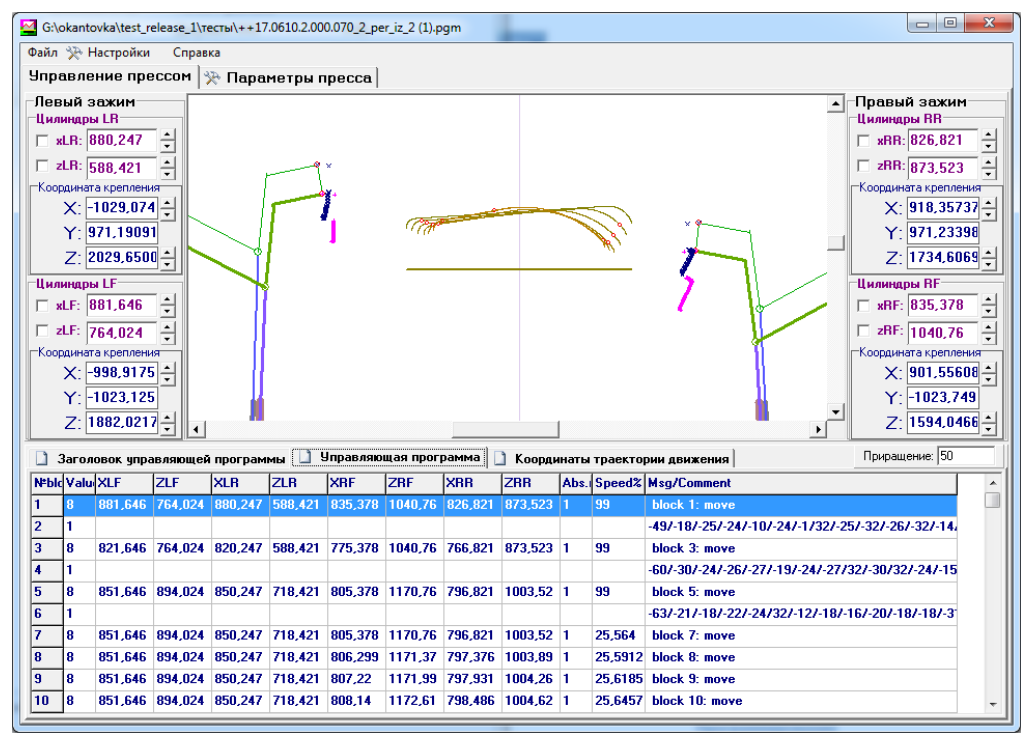

Fig. 6. Software for processing the NC of the FET stretching press

This work was financially supported by the Russian Science Foundation (Grant no. 21-1100165).

\section{References}

[1] A.I.Oleinik, A.I.Pekarsh, Integrated design for the production of monolithic panels., Moscow: Ecom., 2009. DOI: 10.1007/s10808-010-0074-2

[2] B.D.Annin, A.I.Oleynikov, K.S.Bormotin, Modeling of forming of wing panels of the SSJ-100 aircraft, Journal of Applied Mechanics and Technical Physics, 51(2010), no. 4, 579-589.

[3] O.T.Bruhns, Grosse plastische Formanderugen., Mitt. Inst. Mech. / Ruhr-Univ. Bochum, 1991, No 78, 1-149

[4] A.S.Begun, A.A.Burenin, L.V.Kovtanyuk, A.N.Prokudin, On Consistent Shiftability in Mechanisms of Large Irreversible Deformation Production, PMM, 85(2021), Vol. 1, 106-120 (in Russian). DOI: 10.31857/S003282352006003X 
[5] A.A.Burenin, L.V.Kovtanyuk, Large irreversible deformations and elastic aftereffects, Vladivostok, Dalnauka, 2013 (in Russian).

[6] Sheet Metal Industries, 61(1984), no. 2, 74-75.

[7] R.F.Krupskiy, A.A.Krivenok, A.V.Stankevich et al., Modeling the kinetics of movement of the working elements of the FET stretching press, Bulletin of ISTU. Mechanics and mechanical engineering, 92(2014), no. 9, 40-45 (in Russian).

[8] V.A.Mikheev, S.V.Surudin, I.V.Naumenko, E.V.Nazaikinsky, Kinematic method for ensuring preparation of CNC control programs of tightening presses ASV-ALSTHOM, Science, theory, practice of aircraft-industrial cluster of modern Russia. II All-Russian Scientific and Production Conference, Collection of scientific papers, Ulyanovsk: Ulyanovsk State Technical University, 2017, 35-49 (in Russian).

[9] A.A.Veprev, V.I.Zavyalova, Selection of loading scheme and speed of cross-straightening process, Aviation Industry, 1984, no. 12.

[10] A.A.Krivenok, A.V.Stankevich, S.I.Feoktistov et al., Shaping of profile billets with sheet stretching press, Scientists' notes of Komsomolsk-on-Amur state technical university. Sciences of Nature and Technology, 1(2013), no. 2(14), 4-8 (in Russian).

[11] V.A.Mikheev, E.V.Chistyakov, Peculiarities of Calculation of Processes of Composite Shaped Parts, Kuibyshev, 1981, no. 1209, 10-11 (in Russian).

[12] S.V.Surudin, The combination of finite-element modelling and calculation by analytical formulas of the processes of forming a tightening, NATIONAL ASSOCIATION OF SCIENTISTS (NAU), Monthly Scientific Journal, 8(2015), no. 3, Part 3, 139-141 (in Russian).

[13] S.V.Belykh, A.A.Krivenok, V.V.Mironenko, V.A.Mishagin, Determination of the position of the punch in the working space of the FET tightening press during technological preparation of production, Vestnik of Irkutsk State Technical University, 83(2013), no. 12, 36-41 (in Russian).

[14] V.A.Mikheev, F.V.Grechnikov, S.G.Dementiev et al., Modeling of kinematic scheme of a sequential capping of double-convex shells on a FEKD capping press, Izvestia Samarskogo nauchnogo tsentra RAN, 16(2014), no. 6, 172-179 (in Russian).

[15] V.A.Mikheev, F.V.Grechnikov, S.G.Dementiev et al., Investigation of kinematic scheme of a sequential casing stretching of biconvex shape on an FEKD stretching press, Izvestia Samarskogo nauchnogo tsentra RAN, 16(2014), no. 6, 180-186 (in Russian).

[16] V.V.Mironenko, A.A.Cheslavskaya, S.V.Belykh, Modeling of aircraft tightening taking into account the effects arising in the jaw areas, Scientific Notes of KnASTU, 1(2014), no. 2(18), 13-18 (in Russian).

[17] V.A.Mikheev, Stability of double curvature shells in the process of shaping by tightening, Izvestiya Samara Scientific Centre of the Russian Academy of Sciences, 6(2004), no. 2, 408-413 (in Russian).

[18] V.A.Glazunov, A.Sh.Koliskor, A.F.Kraynev, Spatial Mechanisms of Parallel Structure: Tutorial, Moscow, Nauka, 1991 (in Russian). 
[19] J.-P.Merlet, Parallel Robots, Springer Dordrecht, The Netherlands, 2006.

[20] V.A.Glazunov, A.Sh.Koliskor, A.F.Krainev, Development of handling mechanisms of parallel and cross-sectional structure, Problems of Machine-Building and Machine Reliability. Issue. 2, Moscow, Nauka Publisher, 2008, 100-110.

[21] D.C.Yang, T.W.Lee, Feasibility Study of a Platform Type of Robotic Manipulators from a Kinematic Viewpoint, Transactions of ASME Journal of Mechanisms, Transmission and Automation in Design, 106(1984), 191-198.

[22] J.Denavit, R.S.Hartenberg, Kinematic Notation for Lawer-Pair Mechanisms Based on Matrices, J. Appl. Mech., 77(1955), 215-221.

[23] J.S.Andrew, W.W.Charles, Numerical Solutions of Polynomial Systems Arising in Engineering and Science, II - Singapoure: World Scientific, 2005.

[24] S.L.Zenkevich, A.S.Yushchenko, Fundamentals of control of manipulating robots: Text-book for high schools. 2nd edition, revised edition, Moscow, Publishing house of the Moscow State Technical University n.a. N. E. Bauman, 2004.

\title{
О параллельной кинематике обтяжного пресса FET в операциях обтяжки при производстве изделий сложной пространственной геометрии
}

\author{
Антон А. Кривенок \\ Филиал АО "Компания "Сухой" "КнААЗ им. Ю.А. Гагарина" \\ Комсомольск-на-Амуре, Российская Федерация \\ Анатолий А. Буренин \\ Институт машиностроения и металлургии ДВО РАН \\ Хабаровский федеральный исследовательский центр ДВО РАН \\ Хабаровск, Российская Федерация
}

\begin{abstract}
Аннотация. Исследуется кинематика механизма обтяжного пресса с параллельной структурой. Получены кинематические зависимости, которые направлены на задание пространственного положения рабочих органов пресса поперечной обтяжки типа FET и позволяют позиционировать зажимы в каждый момент времени при выполнении технологических операций. Решаются прямая и обратная задачи кинематикой для управления зажимами обтяжного пресса.
\end{abstract}

Ключевые слова: формирование растяжки, растягивающий пресс, FET, кинематика параллельной структуры, задачи прямой и обратной кинематики. 